University of Nebraska - Lincoln

DigitalCommons@University of Nebraska - Lincoln

May 2007

\title{
Comparative Patterns of Predation by Cougars and Recolonizing Wolves in Montana's Madison Range
}

\author{
Todd C. Atwood \\ Utah State University, Logan, UT \\ Eric M. Gese \\ USDA/APHIS/WS National Wildlife Research Center, eric.gese@usu.edu \\ Kyran E. Kunkel \\ Utah State University, Logan, UT
}

Follow this and additional works at: https://digitalcommons.unl.edu/icwdm_usdanwrc

Part of the Environmental Sciences Commons

Atwood, Todd C.; Gese, Eric M.; and Kunkel, Kyran E., "Comparative Patterns of Predation by Cougars and Recolonizing Wolves in Montana's Madison Range" (2007). USDA Wildlife Services - Staff Publications. 696.

https://digitalcommons.unl.edu/icwdm_usdanwrc/696

This Article is brought to you for free and open access by the U.S. Department of Agriculture: Animal and Plant Health Inspection Service at DigitalCommons@University of Nebraska - Lincoln. It has been accepted for inclusion in USDA Wildlife Services - Staff Publications by an authorized administrator of DigitalCommons@University of Nebraska - Lincoln. 


\title{
Comparative Patterns of Predation by Cougars and Recolonizing Wolves in Montana's Madison Range
}

\author{
TODD C. ATWOOD, ${ }^{\mathbf{1 , 2}}$ Department of Wildland Resources, Utah State University, Logan, UT 84322, USA \\ ERIC M. GESE, United States Department of Agriculture-Animal Plant Health Inspection Service-Wildlife Services, National Wildlife Research Center, \\ Department of Wildland Resources, Utah State University, Logan, UT 84322, USA
}

KYRAN E. KUNKEL, Department of Wildland Resources, Utah State University, Logan, UT 84322, USA

\begin{abstract}
Numerous studies have documented how prey may use antipredator strategies to reduce the risk of predation from a single predator. However, when a recolonizing predator enters an already complex predator-prey system, specific antipredator behaviors may conflict and avoidance of one predator may enhance vulnerability to another. We studied the patterns of prey selection by recolonizing wolves (Canis lupus) and cougars (Puma concolor) in response to prey resource selection in the northern Madison Range, Montana, USA. Elk (Cervus elaphus) were the primary prey for wolves, and mule deer (Odocoileus hemionus) were the primary prey for cougars, but elk made up an increasingly greater proportion of cougar kills annually. Although both predators preyed disproportionately on male elk, wolves were most likely to prey on males in poor physical condition. Although we found that the predators partitioned hunting habitats, structural complexity at wolf kill sites increased over time, whereas complexity of cougar kill sites decreased. We concluded that shifts by prey to structurally complex refugia were attempts by formerly naïve prey to lessen predation risk from wolves; nevertheless, shifting to more structurally complex refugia might have made prey more vulnerable to cougars. After a change in predator exposure, use of refugia may represent a compromise to minimize overall risk. As agencies formulate management strategies relative to wolf recolonization, the potential for interactive predation effects (i.e., facilitation or antagonism) should be considered. (JOURNAL OF WILDLIFE MANAGEMENT 71(4):1098-1106; 2007)
\end{abstract}

DOI: $10.2193 / 2006-102$

KEY WORDS antipredator behavior, canid, cougar, felid, habitat, refugia, risk, wolf.

When a recolonizing predator expands into a formerly depopulated ecosystem, complexities may quickly accrue, making it difficult to infer the relative importance of various ecological agents in mediating interactions with prey. This situation may be particularly true when the recolonizing predator must integrate into an already complex predatorprey system. It is generally accepted that prey should behave in a manner that is optimal in deterring predators (Illius and FitzGibbon 1994). Prey can use an array of behaviors to manage predation risk, including spending time vigilant while foraging or resting (Elgar 1989), aggregating in groups (Messier and Barrette 1985, FitzGibbon 1990), spatially dispersing (Bergerud and Page 1987), or seeking refugia habitat (Bergerud et al. 1983, Formanowicz and Bobka 1988). Likewise, predators may use various tactics to keep pace in the behavioral arms race, including modifying space use relative to changes in prey abundance (Kunkel et al. 2004) or by differential assessment of prey vulnerability (FitzGibbon and Fanshawe 1989). The former is strongly influenced by prey spatial ecology and habitat attributes. The latter is likely a function of predator perceptual ability and hunting style. What remains unknown is how quickly and to what extent a recolonizing predator forces prey to modify antipredator behaviors to accommodate a new predation risk.

Effects of habitat attributes on predation risk from a single predator species have been well documented (e.g., Bergerud et al. 1983, Kunkel et al. 2004) and predominantly support a priori expectations that coursing predators (e.g., canids)

\footnotetext{
${ }^{1}$ E-mail: tatwood@azgfd.gov

2 Present address: Arizona Game and Fish Department, 2221 West Greenway Road, Phoenix, AZ 85023, USA
}

require open habitats (Kruuk 1972, Schaller 1972), whereas ambush predators (e.g., felids) rely on structurally complex habitats (Rosenzweig 1966, Caro and FitzGibbon 1992). However, when coursing and ambush predators are considered simultaneously, the role of habitat attributes in mediating prey selection becomes less clear (Kunkel et al. 1999, Husseman et al. 2003, Warfe and Barmuta 2004). For example, in predator recolonization, habitat shifts by prey in response to an additional predation risk may not be immediate. Indeed, if habitat shifts reflect a fear response (Brown et al. 1999), there may be a time lag where formerly naïve prey (Berger et al. 2001) must become cognizant of the threat posed by the recolonizing predator and seek habitats that may mitigate the new predation risk. This scenario can be tested by contrasting key habitat attributes of predator kill sites over time. As prey process information regarding the threat posed by a new predator, behavioral modifications regarding habitat use might arise in subsequent years that lessen predation risk (Testa et al. 2000, Berger et al. 2001).

Physical disadvantages are thought to interact with predator-specific hunting behaviors to determine patterns of prey selection (Estes and Goddard 1967, Murtaugh 1981, Sih and Moore 1990). For example, group hunting by coursing predators can facilitate the capture of larger prey (Rosenzweig 1966, Gittleman 1989), particularly when prey are experiencing the direct effects of poor physical condition (FitzGibbon and Fanshawe 1989, Sinclair and Arcese 1995). In contrast, solitary hunting, common among ambush predators, can impose limits on the size of prey captured (Sunquist and Sunquist 1989, Murphy 1998). It remains unknown to what extent a recolonizing coursing 
predator may alter prey selection of an ambush predator. The most plausible scenario is that risk enhancement may result when nonlethal predation by one predator facilitates lethal predation by another (Kerfoot and Sih 1987, Losey and Denno 1998). If this scenario occurs consistently, disadvantaged prey may, over time, make up greater proportions of prey killed by ambush predators.

We investigated the influence of habitat characteristics and prey physical attributes in mediating predation on elk (Cervus elaphus), mule deer (Odocoileus hemionus), and whitetailed deer (Odocoileus virginianus) by cougars (Puma concolor) and recolonizing wolves (Canis lupus). Specifically, we were interested in whether prey altered their habitat use over time to lessen predation risk and whether wolves and cougars displayed different patterns of prey selection in response. First, we examined whether kill site habitat attributes changed as prey were forced to accommodate a new predation risk (wolves). We predicted that over consecutive years, habitat attributes of wolf kill sites would be dynamic and shift to more structurally complex habitat types (e.g., greater hiding cover, steeper slope), whereas attributes of cougar kill sites would remain static. Next, we characterized predator-specific patterns of prey selection relative to prey relative abundances, demographics, and physical condition. In particular, we were interested in whether prey selected by cougars and wolves over consecutive years differed with respect to physical condition and sex and age classes. We predicted that relative to cougars, 1) wolves would prey disproportionately on physically disadvantaged prey (i.e., young, old, or in poor physical condition), 2) cougars would display no clear pattern of selection based on age or infirmity, and 3) both predators would select prey proportional to their occurrence.

\section{STUDY AREA}

We conducted the study in the Northern Madison Study Area (NMSA; $680 \mathrm{~km}^{2}$ ), located in southwestern Montana's Madison Range of the Rocky Mountains, USA, during January to May 2003-2005. The NMSA was approximately $50 \mathrm{~km}$ northwest of Yellowstone National Park and was bordered on the east by the Gallatin River, on the west by the Madison River, and on the south by the Spanish Peaks of the Gallatin National Forest (Fig. 1). Shrub steppe habitat $\left(535 \mathrm{~km}^{2}\right)$ dominated the NMSA; coniferous forest $\left(145 \mathrm{~km}^{2}\right)$ made up approximately $23 \%$ of the remaining area. Elevations ranged from 2,500 $\mathrm{m}$ in the Spanish Peaks to $1,300 \mathrm{~m}$ on the Madison River floodplain. Elevation changes mediated an ecological gradient varying from dry grassland-juniper (Juniperus scopulorum) savannah at lower elevations to closed canopy Douglas-fir (Pseudotsuga menziesii) or lodgepole pine (Pinus contorta) forests on moist sites at higher elevations. High-elevation dry sites occurred on southern exposures and ridgelines and were composed predominantly of mountain big sage (Artemesia tridentada tridentata)-grassland mosaics. Temperatures ranged from highs of $21-32^{\circ} \mathrm{C}$ in the summer to lows of $-34^{\circ} \mathrm{C}$ in the winter. A suite of predators were present on the NMSA,

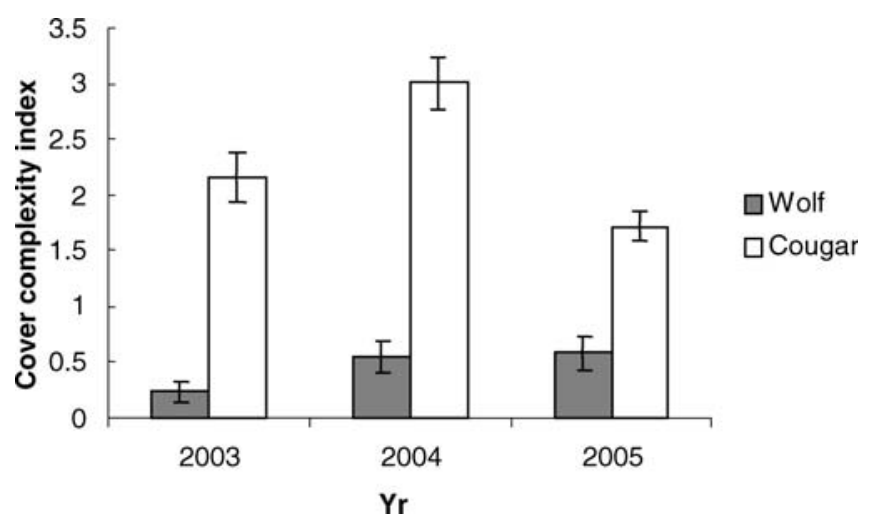

Figure 1. Yearly mean cover complexity index values for wolf and cougar kill site locations on the Northern Madison Study Area, southwest Montana, USA, 2003-2005. Bars represent the standard error of the estimate.

including grizzly bears (Ursus arctos horribilis), black bears (Ursus americanus), cougars, coyotes (Canis latrans), and gray wolves. Wolves recolonized the NMSA in winter 2002, and they represented the recolonizing front of wolves in the Madison Range. Ungulates present on the NMSA included elk, mule deer, white-tailed deer, and moose (Alces alces). The NMSA is privately owned, and male elk are managed for trophy hunting with a maximum annual hunter take of approximately $7.5 \%$ per year; females are managed through late-season public hunts in which hunter take can reach 20\% (R. Arnaud, Turner Enterprises, Inc., personal communication).

\section{METHODS}

We estimated population sizes for elk, white-tailed deer, and mule deer and the age and sex structure for elk from aerial surveys conducted yearly in March. We conducted additional ground surveys after aerial surveys to estimate white-tailed and mule deer age and sex structures. We used 4 fixed transects, ranging from $11 \mathrm{~km}$ to $19 \mathrm{~km}$ in length and located within deer winter ranges, for our ground surveys. We drove each transect over 4 consecutive evenings, and, for each transect, we averaged age (fawn and ad) and sex structure before combining them to provide an estimate for the entire study area. We monitored a single wolf pack (Bear Trap pack) on the study site via visual observation and snow-tracking. Wolf pack size ranged from 2 animals to 8 animals, one of which was radiocollared and subsequently dispersed. Over the duration of the study, the Bear Trap pack averaged 5 individuals. An unknown number of cougars resided in the study area, and we monitored them via snow-tracking. Our research and handling protocols were reviewed and approved by Institutional Animal Care and Use Committees at the National Wildlife Research Center and Utah State University.

\section{Ungulate Carcass Location and Examination}

We located predator-killed ungulates by backtracking wolves and cougars to kill sites, investigating areas where scavenging birds had aggregated, homing in on mortality 
signals from radiocollared mule deer, and searching along 25 transects on a 3-week rotation within wolf and cougar territories. Transect length was dictated by proximity to study area boundaries, and we searched each transect with 2-4 individuals walking parallel to the origin line and spaced at $50-\mathrm{m}$ intervals. Before each rotation, we randomized transect starting points and directions. This method should have ensured that, over time, we searched all habitat types available to wolves and cougars, thereby minimizing possible habitat-specific search bias. When we located a carcass, we first determined the cause of death (e.g., starvation, predation, human-caused), and, for predation, we identified the predator species responsible for the mortality. We used a key adapted from Kunkel et al. (1999) to characterize predator-specific injury patterns and behavior, such as point of attack, method of killing, diameter and spacing of puncture wounds, and carcass location. We differentiated kills from scavenging by the occurrence of chase trails and the presence of subcutaneous hemorrhaging.

We examined kills for physical abnormalities and collected femur bones, mandible bones, or both for marrow fat analysis. Marrow fat analysis provides a measurement of prestarvation absolute physical condition (Mech and DelGuidice 1985), and it can be used to qualitatively classify prey condition at the time of death. We removed and weighed a 5-7-cm sample of marrow from the central portion of the bone. We then oven-dried the sample at $60^{\circ}$ $\mathrm{C}$ for 48 hours and reweighed to calculate the dry-to-wet mass of fat (Neiland 1970). For kills in which only mandibles were available, we followed the procedure outlined in Husseman et al. (2004) to adjust mandible fat values to femur fat equivalents. We estimated prey age based on patterns of tooth eruption and wear (Robinette et al. 1957); we then classified animals as juveniles or adults.

\section{Characterization of Kill Site Attributes and Ungulate Habitat Selection}

To determine the relationships between prey resource selection (elk and mule deer) and habitat at kill sites, we measured percent hiding cover, percent canopy coverage, physiography (\% slope, aspect), and snow depth, and we determined the dominant vegetation class at wolf and cougar kill sites and point locations obtained from observing mule deer and elk. We determined percent hiding cover, expressed as the mean of 4 measurements taken from the cardinal directions (Kunkel 1997), by visually estimating the percentage of an elk or deer obscured at $30 \mathrm{~m}$. We estimated percent canopy coverage, expressed as a continuous percentage (Kunkel 1997), by counting the number of points under canopy at 2-m intervals along 2 (one northsouth, one east-west) $30-\mathrm{m}$ perpendicular transects centered on the carcass. We located mule deer by using radiotelemetry and direct observation via $15-45 \times$ spotting scopes. We located elk opportunistically while observing mule deer or while searching transects for predator kills. We collected data on habitat attributes after mule deer and elk left the general area. We considered point locations separated by a 24-hour interval to be spatially independent.
We used forward stepwise ( $\alpha=0.05$ to enter and remain) logistic regression to evaluate whether vegetative and physiographic characteristics of cougar and wolf kill sites differed from resources selected by prey. We controlled for multicollinearity by eliminating any one of a pair of variables with $r^{2} \geq 0.50$. For models of kill site attributes, predator species was the dependent variable, with wolf used as the reference, and independent variables were percent hiding cover, canopy cover, percent slope, aspect, snow depth, and vegetation classes of riparian, forest, juniper canyon, shrub steppe, and grassland. We included categorical vegetation class and aspect variables in models by using dummy variable coding, excluding the reference categories (shrub steppe and north). We evaluated the same group of covariates for models of prey resource selection, comparing used locations to paired random available locations separated by a distance of $500 \mathrm{~m}$. For all logistic regression analyses, we checked continuous variables for conformity to linearity by using the quartile method (Hosmer and Lemeshow 2000). We ensured final model fit by testing with the Hosmer and Lemeshow goodness-of-fit statistic (H-L stat; Hosmer and Lemeshow 2000). We used Akaike's Information Criterion with a small sample size correction factor $\left(\mathrm{AIC}_{c}\right)$ to determine which parameters we retained in regression models; we considered $\mathrm{AIC}_{c}$ values $>2.0$ to be significant (Burnham and Anderson 1998).

\section{Assessment of Temporal Changes in Vegetation Complexity at Kill Sites}

We assessed the potential for interactive effects of time and predator species on kill site vegetation complexity by calculating a cover complexity index (CCI) for each wolf and cougar kill site. We calculated the CCI by using percent slope and hiding cover, physiographic characteristics most influential in identifying disparate habitat types (i.e., simple as opposed to structurally complex; Attrill et al. 2000) on the NMSA. Because we were interested in whether kill site cover complexity remained static over consecutive years, we calculated the index where $\mathrm{CCI}=\left(\mathrm{x}_{\%}\right.$ slope $\left./ \bar{x}_{i}\right) \times\left(\mathrm{x}_{\%}\right.$ hidecover $/$ $\left.\bar{x}_{\% \text { hidecover }} i\right)$, and $i$ is focal year. Based on a priori expectations of wolves inducing prey to shift to more structurally complex refugia, we anticipated increases in yearly mean CCI values (prediction i). We tested for the interactive effects of time and predator species on the CCI by performing an unbalanced 2-way factorial analysis of variance (ANOVA; Zar 1999) with predator species and year as main effects.

\section{Patterns of Prey Selection}

We used Poisson distributed 2-factor log-linear analyses (Agresti 1990) to examine the interaction between year and prey species selected by the two predators. We used Pearson chi-square analysis (Zar 1999) to assess associations between age and sex of prey selected. We used a forward stepwise logistic regression to identify factors characterizing prey selected by wolves versus cougars (Hosmer and Lemeshow 2000). Independent variables evaluated included prey species, sex, age, percent femur fat, year, and month of kill. 


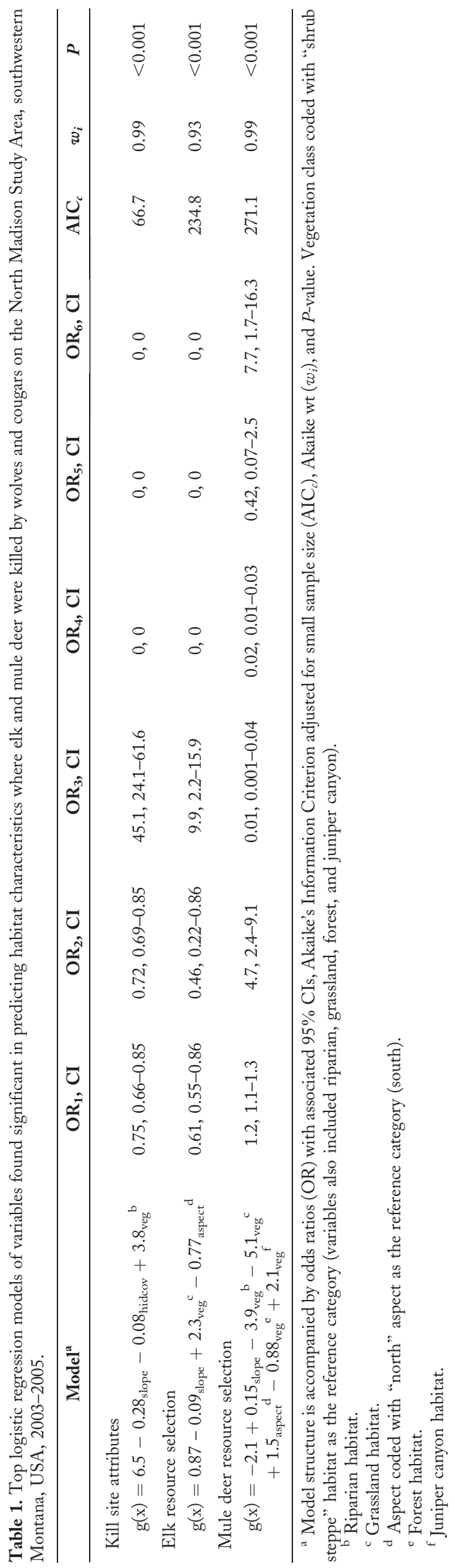

The conservative management of hunter-killed male elk relative to females resulted in a near even sex ratio $\left(\bar{x}_{2003-2005}\right.$ $=1.1 \mathrm{M}: 1.0 \mathrm{~F}$ ). Thus, we felt it prudent to perform a second regression analysis after removing adult male elk from the data set to eliminate the potential effect of percent femur fat bias on parameter estimation (Husseman et al. 2003). Male elk expend considerable energy during the rut and probably enter winter in poorer physical condition than female elk. We further tested for differences in the percent femur fat in adult elk by using an unbalanced factorial ANOVA, with month of kill as a blocking factor and predator species and year as main effects. We normalized femur fat percentage distributions with an arcsine of the square root transformation (Krebs 1999).

\section{RESULTS}

We documented 96 wolf-killed and 110 cougar-killed ungulates over the duration of the study. Elk made up the majority $(70 \%)$ of wolf kills, followed by white-tailed deer $(26 \%)$ and mule deer $(4 \%)$. Mule deer were the primary prey $(55 \%)$ of cougars, followed by elk $(35 \%)$ and whitetailed deer $(10 \%)$. Ungulate numbers varied slightly during the study (R. Arnaud, unpublished data). After the arrival of wolves, elk abundance increased $5 \%$ in 2003 , declined $24 \%$ in 2004, and increased $33 \%$ in 2005. Declining elk abundance in 2004 was attributed to a large herd (approx. 550-650 animals) temporarily leaving the study area (R. Arnaud, personal communication). Mule deer abundance increased by an average of $16 \%$ over the duration of our research (R. Arnaud, unpublished data). Throughout the study, elk were numerically superior $\left(2,416 \pm 423 ; \bar{x}_{2003-2005}\right.$ $\pm \mathrm{SE}$ ), and, on average, made up $72 \%$ of the total ungulate availability; white-tailed deer $\left(550 \pm 119 ; \bar{x}_{2003-2005} \pm \mathrm{SE}\right)$ and mule deer $\left(425 \pm 133 ; \bar{x}_{2003-2005} \pm \mathrm{SE}\right)$ made up $16 \%$ and $12 \%$, respectively.

\section{Characteristics of Kill Sites and Resource Selection}

Our comparison of wolf versus cougar kill site habitat attributes provided evidence that the 2 predators partitioned hunting habitat over the duration of the study. Percent slope was the first variable to be retained in the model, followed by percent hiding cover and riparian habitat (Table 1 ). Based on the respective odds ratios, wolf kills were 0.75 $(95 \% \mathrm{CI}=0.66-0.85)$ times as likely to be located on steep slopes (>15\%), $0.72(95 \% \mathrm{CI}=0.69-0.85)$ times as likely to be located in areas characterized by substantial hiding cover, and $45(95 \% \mathrm{CI}=24-62)$ times more likely to occur in riparian habitats compared with cougar kills (Table 1). Substantial differences existed in resource selection between elk and mule deer. The probability of elk occurrence decreased on south aspects $(\beta=-0.77)$, and it was greatest in grasslands $(\beta=2.3)$ and on shallower slopes $(\beta=-0.09)$. The probability of mule deer occurrence increased on south aspects $(\beta=1.5)$, in shrub steppe habitats $(\beta=2.1)$, and with increasing slope $(\beta=0.15)$, and it decreased in riparian $(\beta=-3.9)$ and grassland habitats $(\beta=-5.1)$. All models performed well under additional fit testing and met assumptions of linearity. 

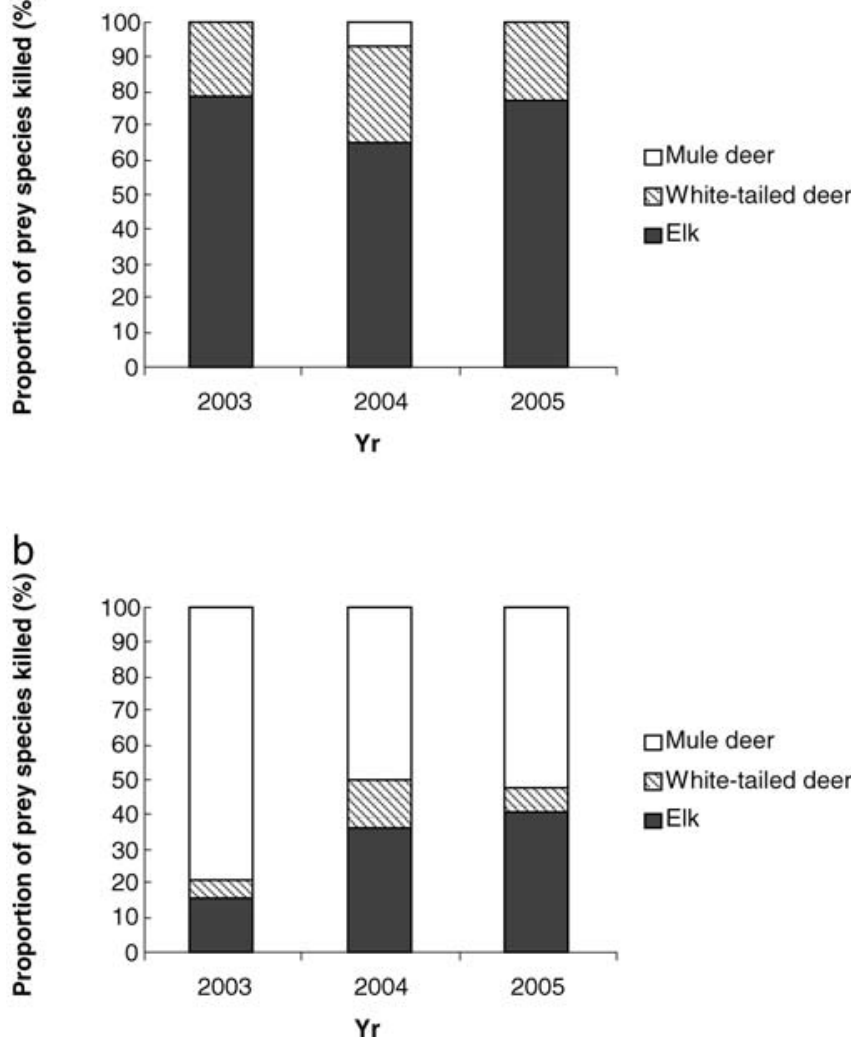

Figure 2. (a) Yearly proportions of elk, white-tailed deer, and mule deer killed by wolves on the Northern Madison Study Area (NMSA), southwestern Montana, USA, 2003-2005. (b) Yearly proportions of elk, white-tailed deer, and mule deer killed by cougars on the NMSA, southwestern Montana, USA, 2003-2005.

Although the habitat characteristics of wolf and cougar kill sites were clearly disparate, evidence also suggested that over consecutive years, wolves were killing prey in habitats characterized by increasingly greater structural complexity (Fig. 1). There was a strong interaction between predator species and year $\left(F_{2,204}=10.42, P<0.001\right)$ relative to incremental change in the mean kill site CCI. Least squares means testing revealed a significant difference in $\mathrm{CCI}$ values, when mean values at wolf kill sites rose sharply in year 2 $\left(\bar{x}_{2003}=0.24,95 \% \mathrm{CI}=0.22-0.26 ; \bar{x}_{2004}=0.55,95 \% \mathrm{CI}=\right.$ $0.47-0.63)$ and increased slightly in year $3\left(\bar{x}_{2005}=0.59\right.$, $95 \% \mathrm{CI}=0.47-0.71$; Fig. 1). Contrary to the yearly increases in wolf kill site CCI values, cougar kill site values declined from year 2 to year 3 (Fig. 1). Thus, in years 2 and 3, wolf kill site structural complexity increased concurrent with declines in vegetation structure at cougar kill sites.

\section{Patterns of Prey Selection}

We restricted log-linear and chi-square analyses of wolf kills to elk and white-tailed deer and cougar kills to elk and mule deer because small sample sizes of wolf-killed mule deer $(n=$ 4) and cougar-killed white-tailed deer $(n=10)$ precluded meaningful analyses. The proportions of elk and whitetailed deer killed by wolves remained consistent over consecutive years $(78 \%$ elk in $2003,65 \%$ in 2004 , and $77 \%$ in 2005; Fig. 2a), and based on log-linear analyses, proportions of wolf-killed prey did not differ relative to yearly availability (yr: $\chi^{2}=0.04, \mathrm{df}=2, P=0.830$; species: $\chi^{2}=1.53$, df $\left.=1, P=0.216\right)$. Contrary to wolves, the proportion of elk and mule deer killed by cougars differed between years ( $\mathrm{yr}: \chi^{2}=6.83, \mathrm{df}=2, P<0.001$; species: $\chi^{2}=$ $8.27, \mathrm{df}=1, P=0.009)$, because elk made up an increasingly greater proportion of yearly kills $(16 \%$ in $2003,36 \%$ in 2004 , and $41 \%$ in 2005; Fig. 2b). There were no betweenyear differences in the proportions of male, female, and juvenile elk killed by wolves $\left(\chi^{2}=7.82, \mathrm{df}=4, P=0.098\right)$, nor were there differences in the age and sex class proportions of elk $\left(\chi^{2}=0.925, \mathrm{df}=4, P=0.921\right)$ or mule deer $\left(\chi^{2}=2.814, \mathrm{df}=4, P=0.589\right)$ selected by cougars. Because we did not find any annual differences in age and sex class selection of elk and mule deer by cougars and wolves, we pooled kill samples from different years for each predator species. The aggregate proportion of elk age and sex classes killed by wolves differed from their availability on the NMSA $\left(\chi^{2}=16.79\right.$, $\left.\mathrm{df}=2, P<0.001\right)$. Relative to availability, wolves selected more males $(64 \%)$ and fewer females $(18 \%)$ than expected. Similarly, cougars killed more male elk $(61 \%)$ and fewer females $(28 \%)$ than expected $\left(\chi^{2}\right.$ $=6.81, \mathrm{df}=2, P=0.033)$. Cougars selected from mule deer age and sex classes in proportion to availability $\left(\chi^{2}=2.03, \mathrm{df}\right.$ $=2, P=0.361$ ), and both predators killed calves (wolves, $18 \%$; cougars, $11 \%$ ) in proportion to their availability.

Logistic regression revealed that prey species, sex, and physical condition influenced patterns of prey selection between wolves and cougars. Prey species, sex, and percent femur fat content (absolute physical condition) were the variables retained in the full model (ad M elk included), and wolves were $1.6(95 \% \mathrm{CI}=0.59-4.1)$ times more likely to kill elk, $2.3(95 \% \mathrm{CI}=1.0-5.3)$ times more likely to kill males, and $7.1(95 \% \mathrm{CI}=3.3-16.7)$ times more likely to kill prey in relatively poor physical condition than cougars (Table 2). When we removed adult males (reduced model) from the data set, prey species and percent femur fat were the most significant variables in predicting predator species (Mech et al. 1995, DelGiudice 1998), indicating that differential predation for males between wolves and cougars occurred primarily among adult elk, and occurred to a lesser degree among white-tailed deer. Femur fat coefficients were similar in the model without adult males. Further analysis of percent femur marrow fat confirmed a robust relationship between prey condition and predator species; after blocking for month of kill, percent femur marrow fat was significantly less in wolf-killed than cougar-killed adult elk (wolf: $\bar{x}=44.1 \pm$ $2.8 \%$; cougar: $\left.\bar{x}=65.6 \pm 2.3 \% ; F_{1,87}=75.43, P<0.001\right)$. There was no significant predator $\times$ year interaction $\left(F_{2,86}=\right.$ $0.16, P=0.85)$. Both logistic regression models performed well under additional model fit tests (full model $\mathrm{H}-\mathrm{L}$ stat $=$ $6.57, \mathrm{df}=7, P=0.47$; reduced model $\mathrm{H}-\mathrm{L}$ stat $=2.24, \mathrm{df}=4$, $P=0.69)$ and met assumptions of linearity.

\section{DISCUSSION}

Results of our study indicate that predator recolonization has the potential to impact aspects of antipredator behavior 
relating to space use, increasing the likelihood of enhanced predation risk for some shared prey. Because we initiated the study at the onset of wolf recolonization, we were able to document patterns of prey selection and predator avoidance when prey were putatively naïve (Berger et al. 2001) to the threat posed by wolves. The response of prey to a recolonizing predator might depend on the extent of prior interaction: prey with little or no experience with a predator may fail to display the appropriate avoidance behaviors. However, threat information can be acquired quickly (Berger et al. 2001, Blumstein et al. 2002), particularly among prey that aggregate (Houston et al. 1993), allowing implementation of avoidance behaviors, such as habitat shifts, to mitigate the new predation risk. Our data support the notion that prey might process threat information rapidly (i.e., within $1 \mathrm{yr}$ ), as evidenced by the sharp increase in CCI values at wolf kill sites in year 2 (2004).

Simple grassland habitats, characterized by shallow slopes with little hiding cover, were the preferred foraging areas for elk, and, similar to other studies, these habitats offered the additional benefit of carrying a diminished risk of predation by cougars (Hornocker 1970, Murphy 1998, Kunkel et al. 1999). Mule deer were most likely to occur in juniper canyon habitats characterized by steeper slopes, greater hiding cover, and little risk of wolf predation, consistent with the attributes of sites where they were killed by cougars. However, unlike mule deer, elk resource selection differed modestly from where they were killed by wolves and substantially from where they were killed by cougars. Decomposition of the CCI at kill sites indicated that percent hiding cover, and to a lesser degree slope, increased over consecutive years at wolf kills, whereas they remained static at cougar kills. Thus, over time, elk kills were distributed in areas of greater structural complexity. Our finding that elk in and around Yellowstone National Park shifted to more structurally complex habitats in response to predation from wolves is consistent with those of Creel and Winnie (2005) and Fortin et al. (2005). These observations suggest a behavioral response in large mammals that is common among prey of various taxa faced with threats from multiple predators: movement to interstitial space where predation risk might be diminished for a primary predator, but slightly heightened for a secondary predator (e.g., Losey and Denno 1998, Novotny et al. 1999, Hampton 2004). These results also indicate there may be a threshold of vegetation structure, above which wolves are mostly unsuccessful in capturing prey. We did not calculate CCI values for point locations of elk and mule deer used in resource selection modeling. However, such an approach, coupled with information on group size, would be valuable in further exploring the nexus between refugia habitat and antipredator behavior.

On the NMSA, structurally complex sites are often associated with canyons and gullies dominated by Rocky Mountain juniper and Douglas-fir, which offer substantial stalking cover for an ambush predator. Accordingly, prey retreating to complex refugia habitat may be reducing their

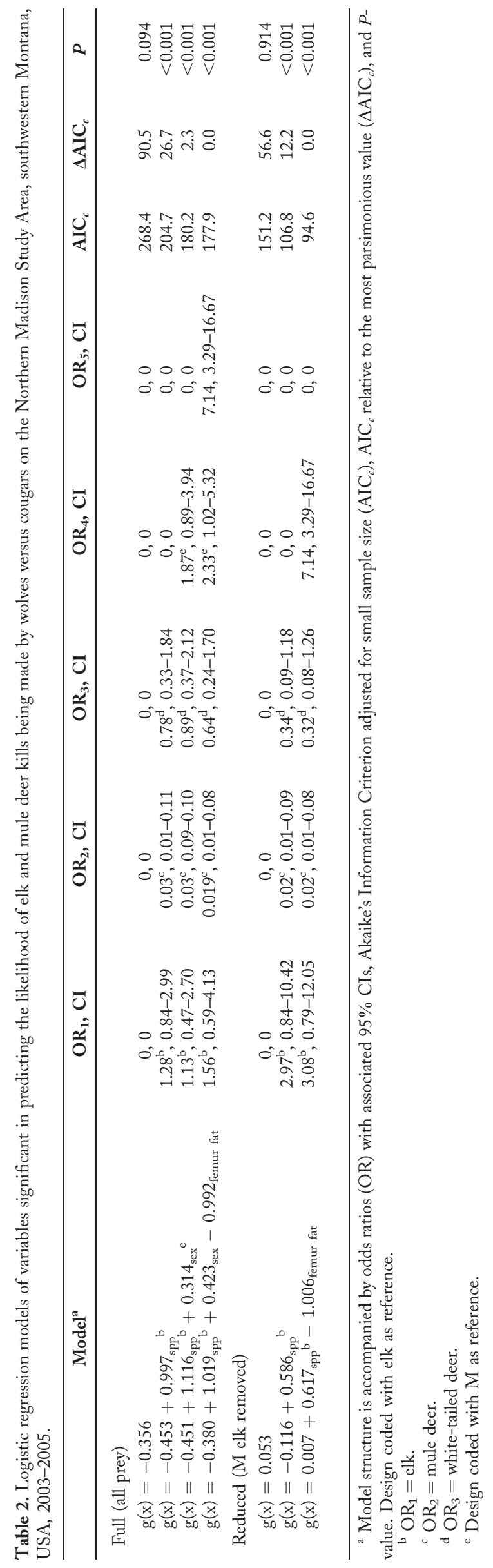

Atwood et al. • Predation by Cougars and Recolonizing Wolves 
risk to predation by wolves only to become more vulnerable to cougars. Indeed, our data indicate that the occurrence of elk kills in increasingly more complex habitats coincided with a rise in the proportion of elk killed by cougars. Perhaps more importantly, the increase in the proportion of elk killed by cougars was not accompanied by a decrease in the proportion of elk killed by wolves. This finding raises the question: Are wolf-induced shifts to refugia by elk enhancing cumulative predation risk from both predators? Wolves selected prey species in proportion to their availability; cougars, in the aggregate, preyed disproportionately on mule deer and underutilized elk. However, beginning in year 2, the proportion of elk killed by cougars increased by $>100 \%$; by year 3 , the proportion of elk to mule deer killed by cougars approached unity. The age and sex class proportions of prey selected by both predators remained consistent over consecutive years with the pooled analysis revealing that adult male elk were disproportionately preyed upon by both wolves and cougars. It seems that predation risk among elk was enhanced, and male elk were most vulnerable.

It is unlikely that habitat shifts alone were responsible for the enhanced predation risk for male elk. Logistic regression results of prey selection (full model) indicated that male elk in poor physical condition were most likely to be killed by wolves. When we dropped male elk from the data set (reduced model), wolves were most likely to kill female elk in poor physical condition. This suggests wolf selection of prey in poor physical condition was not biased by disproportionate selection of male elk and confirms that selection of disadvantaged prey is a particularly important divergent behavior between the 2 predators (Kunkel et al. 1999, Husseman et al. 2003). Indeed, femur fat analysis revealed that wolves generally killed older infirmed elk; however, cougars killed mainly prime age elk in relatively good condition. Prey in declining physical condition may face a trade-off between retreating to structurally complex habitat, which on the NMSA is forage poor, or remaining in open habitats that are generally forage rich (Lima and Dill 1990, McNamara and Houston 1992). It is likely that some male elk, in extremely poor physical condition from the cumulative effects of the rut and a harsh winter, are not able to trade off foraging for a diminished predation risk. Contrary to our predictions, patterns of prey selection based on physical condition were consistent between years, which supports theoretical expectations (Rosenzweig 1966, Estes and Goddard 1967, Caro and FitzGibbon 1992) regardless of whether prey were naïve or savvy.

An interesting, and certainly not ancillary, finding of our research has been the effect of recolonizing wolves on mule deer. It can be argued, despite the systematic use of search transects, that our study design had a methodological bias toward the recovery of predator-killed mule deer: we radiocollared mule deer, but not elk. This putative bias should have led to sampling a greater proportion of mule deer mortalities and underestimating predation effects on elk. Yet, our results indicate wolf predation on mule deer was negligible, whereas cougar predation on mule deer declined as predation on elk increased. It would seem that wolf recolonization, in the short term, had little direct effect on mule deer survival. Indirect effects may be harder to quantify, and we can envision 2 likely scenarios in which wolf recolonization, via wolf-mediated antipredator behavior in elk, may indirectly influence predation risk to mule deer in areas where elk are numerically superior. First, on the NMSA, elk have been observed to displace mule deer from prime foraging habitat while on winter range (Atwood 2006). Elk typically move around winter range in groups of 100-200 females; mule deer groups may range from 1 individual to 15 individuals. Large groups of elk easily displace mule deer from open savannah habitats; mule deer retreat to structurally complex habitats in response. Thus, elk may be buffering mule deer from wolf predation by evicting mule deer from prime wolf hunting habitats. This scenario also may help explain why cougars preyed disproportionately on mule deer on the NMSA. Second, results from our study and other studies (Creel and Winnie 2005, Fortin et al. 2005) suggest that wolf activity can induce habitat shifts in elk, presumably to ameliorate predation risk from wolves. Temporary shifts to structurally complex habitats by elk may expose them to greater predation risk from cougars, but they may dilute the risk of predation for mule deer. Because our data provide some support for both scenarios, further research in this area is warranted.

\section{MANAGEMENT IMPLICATIONS}

Results from this work suggest 2 scenarios in which management may influence multiple predator effects on shared prey. First, wolves may prove useful in reducing cougar predation on mule deer. In areas where elk and mule deer share winter range, and mule deer numbers are declining, wolf recolonization may indirectly benefit mule deer via predator-adaptive behavioral changes in elk (Creel and Winnie 2005). For example, our work shows wolfinduced shifts to refugia by elk diluted cumulative predation risk for mule deer. If sustained, reduced predation on mule deer may help spur an increase in population numbers and create momentum to overcome downward population trends in some areas. Likewise, short-term enhanced cumulative predation on elk may aid in reducing the strength of competitive interactions between elk and mule deer. Second, in areas where enhanced predation risk is a concern, the most effective strategy to ameliorate predation risk may be to reduce hunting success of the dominant predator through manipulation of food and cover (Kunkel and Pletscher 2001). For example, prescribed burns in winter ranges can reduce felid stalking cover and improve browse production. Conversely, to reduce wolf kill rates, areas surrounding winter ranges could be managed for contiguous blocks of dense timber or nonlinear corridors to reduce the ease of wolf travel (Bergerud 1981, McNay and Voller 1995). Whatever the course of action, we recommend applying 
manipulations as experiments conducted as integral parts of adaptive management programs.

\section{ACKNOWLEDGMENTS}

We gratefully acknowledge the financial support provided by the United States Department of Agriculture-Animal Plant Health Inspection Service-Wildlife Services, National Wildlife Research Center, Utah State University Presidential Fellowship Program, Boone and Crockett Club, and Pope and Young Club. Turner Enterprises, Inc., and the Turner Endangered Species Fund assisted with logistical support. B. Beehler, J. Brown, A. Corcoran, A. Nelson, and K. Nittinger provided valuable assistance in the field. We thank V. Asher and M. Phillips of the Turner Endangered Species Fund, M. Kossler of Turner Enterprises, Inc., R. Arnaud and J. Doran of Montana Outfitters, and D. Pac of Montana Fish, Wildlife, and Parks for advice and help with various aspects of this research. Comments from R. Coss, K. Smallwood, and an anonymous reviewer greatly improved an earlier version of this article. Finally, we thank T. Turner and B. Turner for providing access to the Northern Madison Study Area.

\section{LITERATURE CITED}

Agresti, A. 1990. Categorical data analysis. John Wiley and Sons, New York, New York, USA.

Attrill, M. J., J. A. Strong, and A. A. Rowden. 2000. Are macroinvertebrate communities influenced by seagrass structural complexity? Ecography 23: $114-121$.

Atwood, T. C. 2006. Wolves, coyotes, elk, and mule deer: predator-prey behavioral interactions in southwestern Montana. Dissertation, Utah State University, Logan, USA.

Berger, J., J. E. Swenson, and I. Persson. 2001. Recolonizing carnivores and naïve prey: conservation lessons from the Pleistocene extinctions. Science 291:1036-1039.

Bergerud, A. T. 1981. The decline of moose in Ontario-a different view. Alces 17:30-43.

Bergerud, A. T., H. E. Butler, and D. R. Miller. 1983. Antipredator tactics of calving caribou: dispersion in mountains. Canadian Journal of Zoology 62:1566-1575.

Bergerud, A. T., and R. E. Page. 1987. Displacement and dispersion of parturient caribou at calving as antipredator tactics. Canadian Journal of Zoology 65:1597-1606.

Blumstein, D. T., M. Mari, J. C. Daniel, J. G. Ardron, A. S. Griffin, and C. S. Evans. 2002. Olfactory predator recognition: wallabies may have to learn to be wary. Animal Conservation 5:87-93.

Brown, J. S., J. W. Laundre, and M. Gurung. 1999. The ecology of fear: optimal foraging, game theory, and trophic interactions. Journal of Mammalogy 80:385-399.

Burnham, K. P., and D. R. Anderson. 1998. Model selection and inference: a practical information-theoretic approach. Springer-Verlag, New York, New York, USA

Caro, T. M., and C. D. FitzGibbon. 1992. Large carnivores and their prey: the quick and the dead. Pages 117-142 in M. J. Crawley, editor. Natural enemies. Blackwell Scientific, Malden, Massachusetts, USA.

Creel, S., and J. A. Winnie, Jr. 2005. Responses of elk herd size to finescale spatial and temporal variation in the risk of predation by wolves. Animal Behaviour 69:1181-1189.

DelGiudice, G. D. 1998. Surplus killing of white-tailed deer by wolves in northcentral Minnesota. Journal of Mammalogy 79:227-235.

Elgar, M. A. 1989. Predator vigilance and group size in mammals and birds: a critical review of the empirical evidence. Biological Review 64:1333.

Estes, R. D., and J. Goddard. 1967. Prey selection and hunting behavior of the African wild dog. Journal of Wildlife Management 31:52-70.
FitzGibbon, C. D. 1990. Mixed species grouping in Thomson's and Grant's gazelles: the antipredator benefits. Animal Behaviour 39:1116-1126.

FitzGibbon, C. D., and J. H. Fanshawe. 1989. The condition and age of Thomson's gazelles killed by cheetahs and wild dogs. Journal of Zoology 218:99-107.

Formanowicz, D. R., and M. S. Bobka. 1988 Predation risk and microhabitat preference: an experimental study of the behavioral responses of prey and predator. American Midland Naturalist 121:379386.

Fortin, D., H. L. Beyer, M. S. Boyce, D. W. Smith, T. Duchesne, and J. S. Mao. 2005. Wolves influence elk movements: behavior shapes a trophic cascade in Yellowstone National Park. Ecology 86:1320-1330.

Gittleman, J. L. 1989. Carnivore group living: comparative trends in carnivore behavior, ecology, and evolution. Pages 183-207 in J. L. Gittleman, editor. Carnivore behavior, ecology, and evolution. Cornell University Press, Ithaca, New York, USA.

Hampton, S. 2004. Habitat overlap of enemies: temporal patterns and the role of spatial complexity. Oecologia 138:475-484.

Hornocker, M. G. 1970. An analysis of mountain lion predation upon mule deer and elk in the Idaho Primitive Area. Wildlife Monograph 21.

Hosmer, D. W., and S. Lemeshow. 2000. Applied logistic regression. John Wiley and Sons, Hoboken, New Jersey, USA.

Houston, A. I., J. M. McNamara, and J. M. Hutchinson. 1993. General results concerning the trade-off between gaining energy and avoiding predation. Proceedings of the Royal Society of London Series B, Biological Sciences 341:375-397.

Husseman, J. S., D. L. Murray, G. Power, and C. M. Mack. 2004 Correlation patterns of marrow fat in Rocky Mountain elk bones. Journal of Wildlife Management 67:742-746.

Husseman, J. S., D. L. Murray, G. Power, C. M. Mack, C. R. Wegner, and H. Quigley. 2003. Assessing differential prey selection patterns between two sympatric large carnivores. Oikos 101:591-601.

Illius, A. W., and C. D. FitzGibbon. 1994. Costs of vigilance in foraging ungulates. Animal Behaviour 47:481-484.

Kerfoot, W. C., and A. Sih. 1987. Predation: direct and indirect impacts on aquatic communities. University Press of New England, New Haven, Connecticut, USA.

Krebs, C. J. 1999. Ecological methodology. Benjamin Cummings Press, Menlo Park, California, USA.

Kruuk, H. 1972. The spotted hyena. University of Chicago Press, Chicago, Illinois, USA.

Kunkel, K. E. 1997. Predation by wolves and other large carnivores in northwestern Montana and southeastern British Columbia. Dissertation, University of Montana, Missoula, USA

Kunkel, K. E., and D. H. Pletscher. 2001. Winter hunting patterns of wolves in and near Glacier National Park, Montana. Journal of Wildlife Management 65:520-530.

Kunkel, K. E., D. H. Pletscher, D. K. Boyd, R. R. Ream, and M. W. Fairchild. 2004. Factors correlated with foraging behavior of wolves in and near Glacier National Park, Montana. Journal of Wildlife Management 68:167-178.

Kunkel, K. E., T. K. Ruth, D. H. Pletscher, and M. G. Hornocker. 1999. Winter prey selection by wolves and cougars in and near Glacier National Park, Montana. Journal of Wildlife Management 63:901-910.

Lima, S. L., and L. M. Dill. 1990. Behavioural decisions made under the risk of predation: a review and prospectus. Canadian Journal of Zoology 68:619-640.

McNamara, J. M., and A. I. Houston. 1992. Evolutionary stable levels of vigilance as a function of group size. Animal Behaviour 43:641-658.

McNay, R. S., and J. M. Voller. 1995. Mortality causes and survival estimates for adult female Colombian black-tailed deer. Journal of Wildlife Management 59:138-146.

Mech, L. D., and G. D. DelGuidice. 1985. Limitations of the marrow-fat technique as an indicator of body condition. Wildlife Society Bulletin 13: 204-206.

Mech, L. D., T. J. Meier, J. W. Burch, and L. G. Adams. 1995. Patterns of prey selection by wolves in Denali National Park, Alaska. Pages 231-244 in L. D. Carbyn, S. H. Fritts, and D. R. Seip, editors. Ecology and Conservation of Wolves in a Changing World. Proceedings of the Second North American Symposium on Wolves, Canadian Circumpolar Institute, Occasional Publication 35, Edmonton, Alberta, Canada.

Messier, F., and C. Barrette. 1985. The efficacy of yarding behavior by 
white-tailed deer as an antipredator strategy. Canadian Journal of Zoology 63:785-789.

Murphy, K. 1998. The ecology of the cougar (Puma concolor) in the Northern Yellowstone ecosystem: interactions with prey, bears, and humans. Dissertation, University of Idaho, Moscow, USA.

Murtaugh, P. A. 1981. Size-selective predation on Daphnia by Neomysis mercedis. Ecology 62:894-900.

Neiland, K. A. 1970. Weight of dried marrow as indicator of fat in caribou femurs. Journal of Wildlife Management 34:904-907.

Novotny, V., Y. Basset, J. Auga, W. Boen, C. Dal, P. Drozd, M. Kasbal, B. Isua, R. Kutil, M. Manumbor, and K. Molem. 1999. Predation risk for herbivorous insects on tropical vegetation: a search for enemy-free space and time. Australian Journal of Ecology 24:477-483.

Robinette, L. W., D. A. Jones, G. Rogers, and J. S. Gashwiler. 1957. Notes on tooth development wear for Rocky Mountain mule deer. Journal of Wildlife Management 21:134-153.

Rosenzweig, M. L. 1966. Community structure in sympatric carnivora. Journal of Mammalogy 47:602-612.
Schaller, G. B. 1972. The Serengeti lion: a study of predator-prey relationships. University of Chicago Press, Chicago, Illinois, USA.

Sinclair, A. R. E., and P. Arcese. 1995. Population consequences of predator-sensitive foraging: the Serengeti wildebeest. Ecology 76:882891.

Sunquist, M. E., and F. C. Sunquist. 1989. Ecological constraints on predation by large felids. Pages 382-409 in J. L. Gittleman, editor. Carnivore behavior, ecology, and evolution. Cornell University Press, Ithaca, New York, USA.

Testa, J. W., E. F. Becker, and G. R. Lee. 2000. Temporal patterns in the survival of twin and single moose (Alces alces) calves in south-central Alaska. Journal of Mammalogy 81:162-168.

Warfe, D. M., and L. A. Barmuta. 2004. Habitat structural complexity mediates the foraging success of multiple predator species. Oecologia 141: 171-178.

Zar, J. H. 1999. Biostatistical Analysis. Fourth edition. Prentice-Hall, Upper Saddle River, New Jersey, USA.

Associate Editor: Morrison. 